\title{
Expression of $A C P 6$ is an independent prognostic factor for poor survival in patients with esophageal squamous cell carcinoma
}

\author{
TAKUYA ANDO, HIDEYUKI ISHIGURO, YOSHIYUKI KUWABARA, MASAHIRO KIMURA, \\ AKIRA MITSUI, HIROKI KUREHARA, NOBUYOSHI SUGITO, KEISUKE TOMODA, \\ RYOTA MORI, NOBUHIRO TAKASHIMA, RYO OGAWA and YOSHITAKA FUJII \\ Department of Surgery II, Nagoya City University Medical School, \\ 1 Kawasumi, Mizuho-cho, Mizuho-ku, Nagoya 467-8601, Japan
}

Received December 2, 2005; Accepted February 7, 2006

\begin{abstract}
ACP6 (acid phosphatase 6, lysophosphatidic) is a lysophosphatidic acid (LPA)-specific phosphatase that hydrolyzes LPA to monoacylglycerol and is involved in lipid metabolism in the mitochondria. Its role in oncogenesis and cancer progression has not been studied. In this study, we examined the expression of ACP6 mRNA and evaluated its clinical significance in esophageal squamous cell carcinoma (ESCC). Expression of ACP6 mRNA was quantified by realtime reverse transcription polymerase chain reaction using the LightCycler in 70 esophageal ESCC specimens and their paired normal esophageal mucosa. The data were analyzed with reference to clinicopathological factors. ACP6 mRNA expression in esophageal cancer tissue was significantly lower than that in corresponding normal esophageal mucosa $(\mathrm{P}=0.0301)$. Among the esophageal cancer tissues, ACP6 mRNA expression significantly correlated with local tumor invasion ( $\mathrm{T}$ factor, $\mathrm{P}=0.0461$ ) and lymph node metastasis $(\mathrm{P}=0.0128)$. Furthermore, low ACP6 mRNA expression was associated with a significantly shorter survival time compared with high expression (log-rank test, $\mathrm{P}=0.0358$ ). In multivariate analysis, ACP6 mRNA expression emerged as a significant independent factor $(\mathrm{P}=0.0148)$. Impaired $A C P 6$ expression may lead to more aggressive invasion of ESCC, and ACP6 mRNA expression level could be an independent prognostic factor for patients with ESCC.
\end{abstract}

\section{Introduction}

ESCC is the sixth most frequent cancer in Japan, and the number of deaths due to this cancer has been steadily

Correspondence to: Dr Hideyuki Ishiguro, Department of Surgery II, Nagoya City University Medical School, 1 Kawasumi, Mizuho-cho, Mizuho-ku, Nagoya 467-8601, Japan

E-mail: h-ishi@med.nagoya-cu.ac.jp

Key words: ACP6, esophageal cancer, independent prognosis factor, LightCycler increasing. ESCC is often diagnosed at an advanced stage and the prognosis remains poor, prompting the search for new treatment strategies. Although preoperative chemotherapy and chemoradiation therapy are currently used for patients with advanced stage ESCC, their results are not satisfactory. Even among patients with early-stage disease, we have observed many who develop locally recurrent tumors or distant metastases within a short period after curative surgery. Molecular biological studies have revealed that esophageal cancer is caused by the accumulation of multiple genetic defects in dominant oncogenes and tumor suppressor genes. We have also reported that the expression of survivin (1), DFF45/ICAD (2), PTTG (3), chfr (4), PPAR (5) and ERCC3 (6) correlates with the prognosis of patients with esophageal carcinoma.

Lysophosphatidic acid (LPA) is a growth factor-like phospholipid present in serum and many other biological fluids. LPA mediates the most important action and cellular response, including platelet aggregation, smooth muscle contraction, regulation of cell proliferation, transcellular migration and cell survival. LPA also plays important roles in the metabolism of phospholipids inside cells, and is an intermediate lipid in the pathway of phosphatidic acid (PA) synthesis (Fig. 1). LPA and PA are synthesized on the cytosolic side of the mitochondrial outer membrane (MOM). LPA is synthesized from $s n$-glycerol-3 phosphate (G-3-P), and subsequently to PA by acyltransferase. Synthesized PA moves to the inner membrane as a precursor of cardiolipin $(7,8)$, which is an essential phospholipid for the function of mitchondria.

Acid phosphatase 6, lysophosphatidic (ACP6) is an LPAspecific phosphatase that hydrolyzes LPA to monoacylglycerol (MAG) $(9,10)$. ACP6 is also called LPAP, ACPL1 and PACPL1. The structure of this enzyme shows homology to acid phosphatases including human prostatic acid phosphatase, which also has LPA phosphatase activity and degrades LPA (11). Its role in oncogenesis and cancer progression has not been studied.

In this study, we investigated the ACP6 mRNA expression level in ESCC and its paired normal esophageal mucosa by real-time reverse transcription polymerase chain reaction (RT-PCR) using LightCycler. We analyzed the results in reference to the patients' clinicopathological characteristics and effect on the prognosis of ESCC patients. 


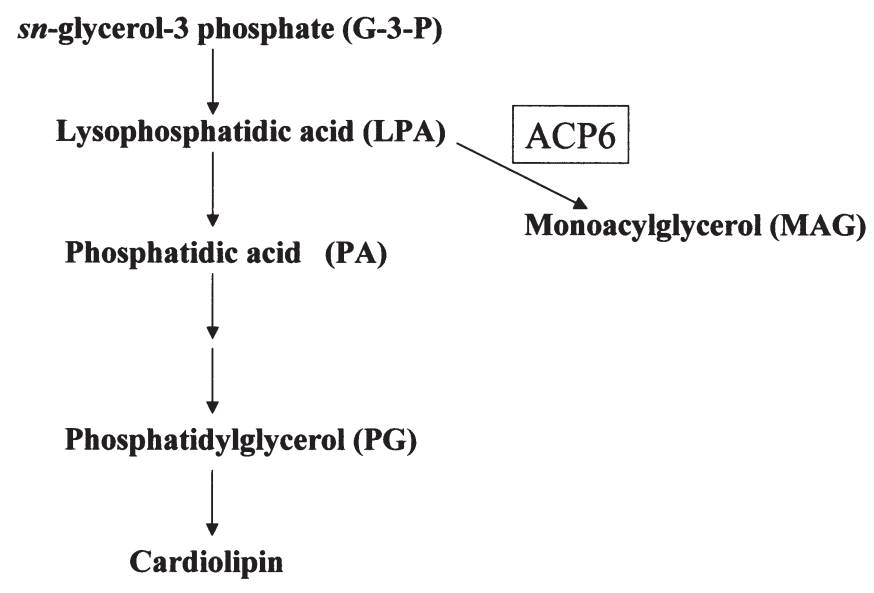

Figure 1. Illustration showing the metabolism of phospholipids, including ACP6. Increased expression of ACP6 is expected to reduce PA through the removal of LPA to MAG, resulting in the reduction of cardiolipin and PG.

\section{Materials and methods}

Cell lines and tissue samples. Samples were obtained from 70 patients with primary esophageal squamous cell carcinomas who had undergone radical esophagectomy at the Department of Surgery II, Nagoya City University Medical School between 1996 and 2001. The study design was approved by the IRB of our university, and written consent was obtained from all patients. Tumors were classified according to the Guidelines for the Clinical and Pathological Studies on Carcinoma of the Esophagus (12). There were 56 males and 14 females, and the mean age was $61.9 \pm 8.9$ years (range, 47-80 years). All samples were frozen immediately in liquid nitrogen and stored at $-80^{\circ} \mathrm{C}$ until use. The characteristics of the 70 patients with ESCC are shown in Table I.

The TE series esophageal cancer cell lines were purchased from the Japanese Cancer Research Resources Bank (JCRB). The SV40-immortalized esophageal cell line, Het-1A, was purchased from the American Type Culture Collection (ATCC). Esophageal cancer TE cells were plated in tissue culture dishes and grown in RPMI-1640 medium (Sigma) with $10 \%$ fetal bovine serum (JRH Bioscience) at $37^{\circ} \mathrm{C}$ in a humidified atmosphere of $95 \%$ air and $5 \% \mathrm{CO}_{2}$. Het-1A cells were grown in LHC-9 serum-free medium (Biofluids, Rockville, MD) in tissue culture dishes at $37^{\circ} \mathrm{C}$ in a humidified atmosphere of $95 \%$ air and $5 \% \mathrm{CO}_{2}$.

RNA extraction and RT-PCR analysis. Total RNA was extracted from esophageal cancer tissue, and its corresponding normal esophageal mucosa was taken from apparently noncancerous mucosa as far away from the tumor as possible, using an Isogen kit (Nippon Gene, Tokyo, Japan) according to the manufacturer's instructions. Total RNA from the cell lines was similarly extracted. The concentration of total RNA was adjusted to $200 \mathrm{ng} / \mathrm{ml}$ using a spectrophotometer. Reverse transcriptional reaction was carried out at $42^{\circ} \mathrm{C}$ for $90 \mathrm{~min}$ and $95^{\circ} \mathrm{C}$ for $5 \mathrm{~min}$ followed by incubation at $72^{\circ} \mathrm{C}$ for $15 \mathrm{~min}$, using $1 \mu \mathrm{g}$ of total RNA, $0.5 \mu \mathrm{g}$ of oligo(dT) primer and Superscript II enzyme (Gibco BRL, Gaithersburg, MD). All samples were quantified after PCR amplification using a
Table I. Correlation of ACP6 mRNA expression in esophageal cancer with clinicopathological factors, including patient and tumor characteristics.

\begin{tabular}{|c|c|c|c|}
\hline Characteristics & $\begin{array}{c}\text { No. of } \\
\text { patients } \\
(\mathrm{n}=70)\end{array}$ & $\begin{array}{c}A C P 6 \text { expression } \\
\text { relative to } \\
\text { GAPDH }^{\mathrm{a}}\end{array}$ & P-value \\
\hline Normal & 70 & $0.291 \pm 0.256$ & \\
\hline Tumor & 70 & $0.213 \pm 0.116$ & 0.0301 \\
\hline \multicolumn{4}{|l|}{ Age at surgery } \\
\hline$<65$ years & 41 & $0.203 \pm 0.125$ & \\
\hline$>65$ years & 29 & $0.227 \pm 0.174$ & 0.9004 \\
\hline \multicolumn{4}{|l|}{ Gender } \\
\hline Male & 56 & $0.209 \pm 0.140$ & \\
\hline Female & 14 & $0.229 \pm 0.174$ & 0.8717 \\
\hline \multicolumn{4}{|c|}{ Pathological stage } \\
\hline 0 & 3 & $0.236 \pm 0.033$ & \\
\hline $\mathrm{I}$ & 4 & $0.364 \pm 0.149$ & \\
\hline II & 11 & $0.251 \pm 0.220$ & \\
\hline III & 23 & $0.210 \pm 0.132$ & \\
\hline IV & 29 & $0.178 \pm 0.119$ & 0.1803 \\
\hline
\end{tabular}

Primary tumor

$\begin{array}{lrr}\mathrm{T} 1 & 9 & 0.296 \pm 0.120 \\ \mathrm{~T} 2 & 9 & 0.211 \pm 0.102 \\ \mathrm{~T} 3 & 32 & 0.224 \pm 0.172 \\ \mathrm{~T} 4 & 20 & 0.160 \pm 0.113\end{array}$

0.0461

Lymph node

metastasis

$\begin{array}{lll}\text { Negative } & 16 & 0.309 \pm 0.191 \\ \text { Positive } & 54 & 0.185 \pm 0.113\end{array}$

0.0128

Histological subtype

$\begin{array}{lrrr}\text { Well } & 27 & 0.188 \pm 0.149 & \\ \text { Moderate } & 31 & 0.225 \pm 0.152 & \\ \text { Poor } & 8 & 0.257 \pm 0.154 & 0.2502 \\ \text { Unknown } & 4 & & \end{array}$

${ }^{a}$ Mean \pm standard deviation (SD). ACP6, acid phosphatase 6, lysophosphatidic; GAPDH, glyceraldehyde-3-phosphate dehydrogenase.

Lightcycler-Faststart DNA Master Sybr-Green I kit (Roche Molecular Biochemicals, Mannheim, Germany). We used the following set of primers: forward primer ACP6-F, 5-AATG TTTGCCTTGGGAGAGA-3; and reverse primer ACP6-R, 5-AGCAGCTTTGGTAGTTGGGA-3 (the size of the product was $233 \mathrm{bp}$ ). The PCR protocol was initial denaturation at $95^{\circ} \mathrm{C}$ for $10 \mathrm{~min}$, followed by 45 cycles at $95^{\circ} \mathrm{C}$ for $10 \mathrm{sec}$, annealing at $60^{\circ} \mathrm{C}$ for $5 \mathrm{sec}$, and extension at $72^{\circ} \mathrm{C}$ for $10 \mathrm{sec}$. The PCR product was quantified via the intensity of SybrGreen I at $72^{\circ} \mathrm{C}$.

Statistical analysis. The relative mRNA expression levels $(A C P 6 / G A P D H)$ were calculated from quantified data in 


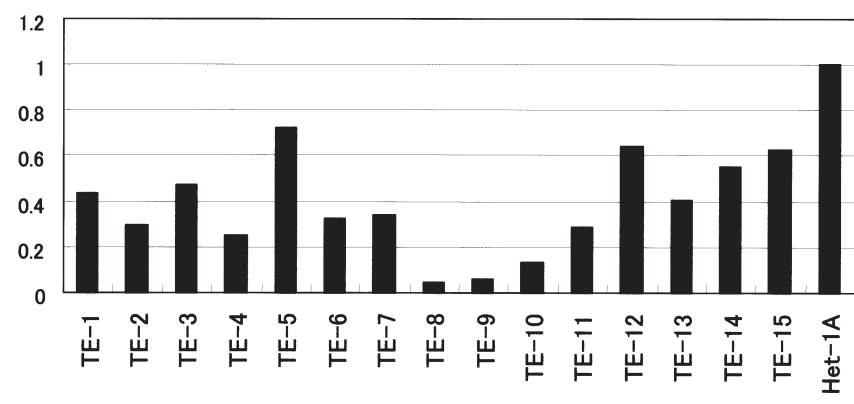

Figure 2. Comparison of $A C P 6 / G A P D H$ mRNA expression levels in cell lines. The expression levels in all esophageal cancer cell lines were lower than that in Het-1A. ACP6/GAPDH mRNA expression in Het-1A was shown as 1 .

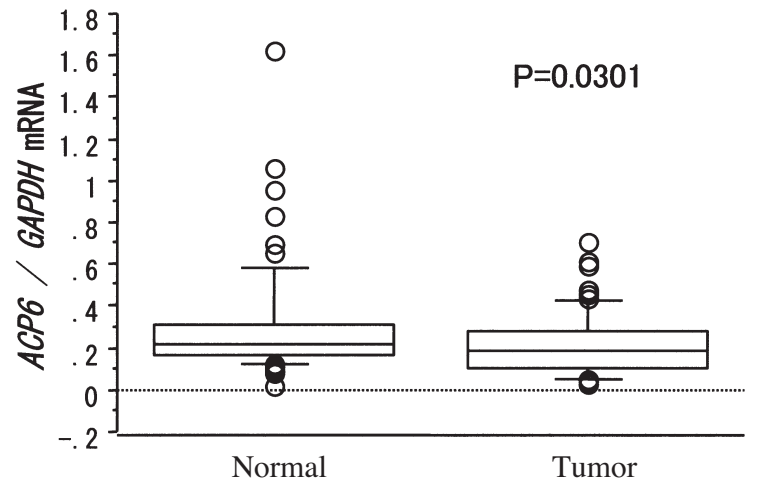

Figure 3. ACP6/GAPDH mRNA expression levels in ESCC tissue were significantly lower than those in the corresponding normal esophageal mucosa $(\mathrm{P}=0.0301$, Wilcoxon signed-ranks test $)$.

reference to the expression level of glyceraldehyde-3phosphate dehydrogenase $(G A P D H)$. Data are expressed as means \pm SD. Statistical analysis was performed using the Stat-View software package (Abacus Concepts, Berkeley, CA). The Wilcoxon signed-ranks test, Mann-Whitney U test, and Kruskal-Wallis test were used to evaluate the significance of differences in expression levels of ACP6 mRNA. The survival of ESCC patients after surgery was examined using the Kaplan-Meier method, and survival times were compared using the log-rank test. Multivariate analysis was performed using the Cox regression model and logistic multivariate regression model. In all analyses, $\mathrm{P}<0.05$ was considered statistically significant.

\section{Results}

ACP6/GAPDH mRNA expression in 15 esophageal cancer cell lines was examined. The levels of expression in all esophageal cancer cell lines were lower than the expression in Het-1A, a normal esophageal cell line (Fig. 2). ACP6 mRNA expression was detectable in all ESCC tissue and noncancerous esophageal mucosa. The levels of expression in ESCC tissue were significantly lower than those of the corresponding normal esophageal mucosa $(0.291 \pm 0.256$ vs. $0.213 \pm 0.146, \mathrm{P}=0.0301$; Wilcoxon signed-ranks test) (Fig. 3 and Table II). We examined the relationship between ACP6
Table II. Univariate analysis.

\begin{tabular}{|c|c|c|c|}
\hline Parameter & $\begin{array}{l}\text { Risk } \\
\text { ratio }\end{array}$ & $95 \% \mathrm{CI}$ & P-value \\
\hline \multicolumn{4}{|l|}{ Age at surgery } \\
\hline$<65$ years & 1 & & \\
\hline$>65$ years & 1.469 & $0.798-2.703$ & 0.2167 \\
\hline \multicolumn{4}{|l|}{ Gender } \\
\hline Female & 1 & & \\
\hline Male & 1.107 & $0.528-2.322$ & 0.7875 \\
\hline \multicolumn{4}{|l|}{ Histological grade } \\
\hline Moderate-poor & 1 & & \\
\hline Well & 1.603 & $0.847-3.032$ & 0.1171 \\
\hline \multicolumn{4}{|l|}{ Primary tumor } \\
\hline $\mathrm{Tl}-2$ & 1 & & \\
\hline $\mathrm{T} 3-4$ & 11.788 & $2.835-49.019$ & $<0.0010$ \\
\hline \multicolumn{4}{|c|}{ Lymph node metastasis } \\
\hline Negative & 1 & & \\
\hline Positive & 5.48 & $1.687-17.798$ & 0.0012 \\
\hline \multicolumn{4}{|c|}{ ACP6 expression (T/N) } \\
\hline High & 1 & & \\
\hline Low & 1.931 & $1.023-3.644$ & 0.0358 \\
\hline
\end{tabular}

CI, confidence interval.

mRNA expression in 70 ESCC samples and the patients' clinicopathological factors (Table I). Of the 70 ESCC samples studied, there were no significant differences in $A C P 6$ mRNA according to age, gender, tumor cell differentiation, and stage. ACP6 mRNA expression levels in patients with ESCC varied significantly according to the tumor status ( $\mathrm{T}$ factor, $\mathrm{P}=0.0461$; Kruskal-Wallis test) (Table I and Fig. 4a). ACP6 mRNA expression levels in patients with locally invasive T3-4 tumors $(0.201 \pm 0.147)$ were significantly lower than those in less aggressive T1-2 tumors $(0.296 \pm 0.120)(\mathrm{P}=0.021$; Mann-Whitney U test). ACP6 mRNA expression levels in patients who had lymph node metastasis $(0.185 \pm 0.118)$ were significantly lower than those in ESCC patients without lymph node metastasis $(0.309 \pm 0.191)(\mathrm{P}=0.0128$; Mann-Whitney $\mathrm{U}$ test) (Table I and Fig. 4b).

We investigated the correlation between ACP6 mRNA expression levels and the survival of ESCC patients after surgery (median follow-up, 23 months). Patients who had low ACP6 mRNA expression levels [indicated as the ratio of $A C P 6$ mRNA expression in the tumor to that in normal esophageal mucosa ( $\mathrm{T}: \mathrm{N}$ ratio) $<0.85, \mathrm{n}=38$ ] had a significantly shorter survival (13.0 \pm 1.862 months) after surgery compared with patients who had high ACP6 mRNA expression levels (T:N ratio $>0.85, \mathrm{n}=32 ; 31.0 \pm 10.16$ months) $(\mathrm{P}=0.0358, \mathrm{log}-$ rank test) (Fig. 5). Among the clinicopathological factors, univariate analysis showed that local invasiveness (risk ratio, 11.788; $\mathrm{P}<0.001$ ), lymph node metastasis (risk ratio, 5.48; $\mathrm{P}=0.0012$ ), and $A C P 6$ expression ( $\mathrm{T}: \mathrm{N}$ ratio) (risk ratio, $1.931 ; \mathrm{P}=0.0358)$ were statistically significant prognostic 
a

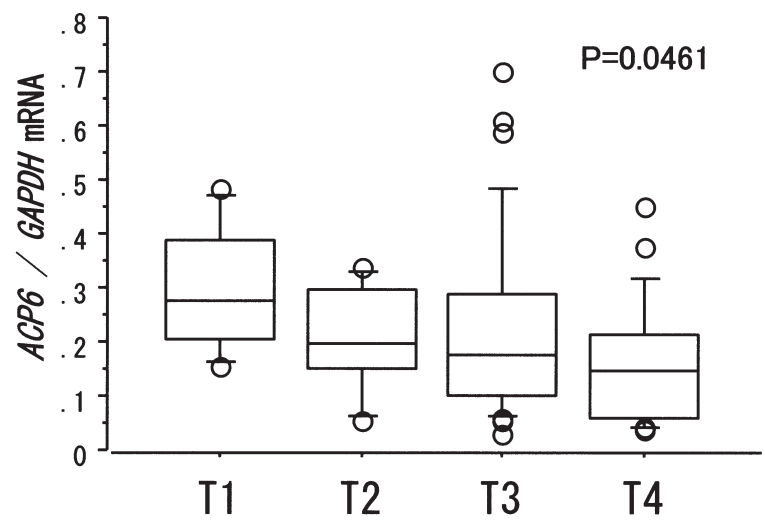

b

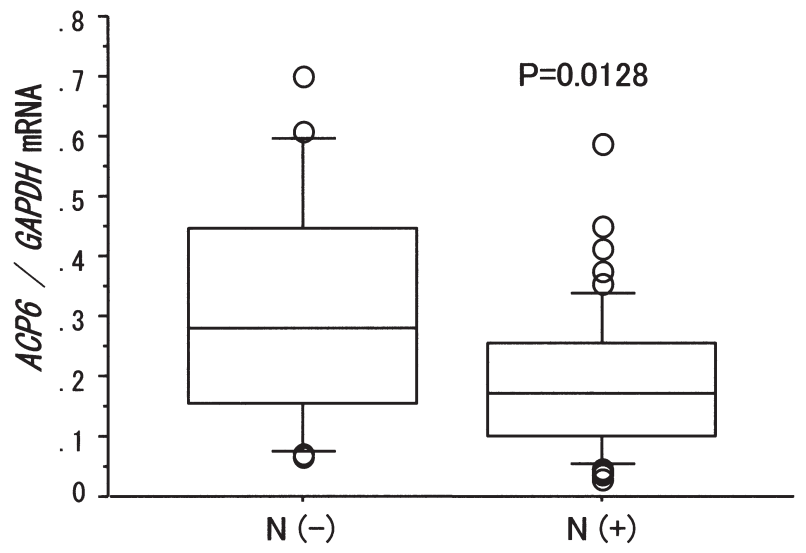

Figure 4. (a) $A C P 6 / G A P D H$ mRNA expression levels in patients with ESCC varied significantly according to tumor status $(\mathrm{P}=0.0461$, Kruskal-Wallis test). (b) ACP6 mRNA expression levels in patients who had lymph node metastasis were significantly lower than the expression levels in ESCC patients without lymph node metastasis ( $\mathrm{P}=0.0128$, Mann-Whitney $\mathrm{U}$ test).

Table III. Multivariate analysis.

\begin{tabular}{lccc}
\hline Parameter & $\begin{array}{c}\text { Risk } \\
\text { ratio }\end{array}$ & $95 \%$ CI & P-value \\
\hline Primary tumor & 1 & & \\
$\quad$ Tl-2 & 9.35 & $2.181-40.088$ & 0.0026 \\
T3-4 & & & \\
Lymph node metastasis & & & \\
$\quad$ Negative & 1 & & 0.0269 \\
$\quad$ Positive & 5.115 & $1.205-21.715$ & \\
ACP6 expression (T/N) & & & \\
$\quad$ High & 1 & & \\
$\quad$ Low & 2.504 & $1.197-5.239$ & 0.0148 \\
\hline
\end{tabular}

CI, confidence interval.

factors (Table II). Multivariate analysis revealed that the extent of the primary tumor $(\mathrm{P}=0.0026)$, lymph node metastasis $(\mathrm{P}=0.0269)$, and $A C P 6$ expression $(\mathrm{T}: \mathrm{N}$ ratio $)(\mathrm{P}=0.0148)$ were independent prognostic factors (Table III).

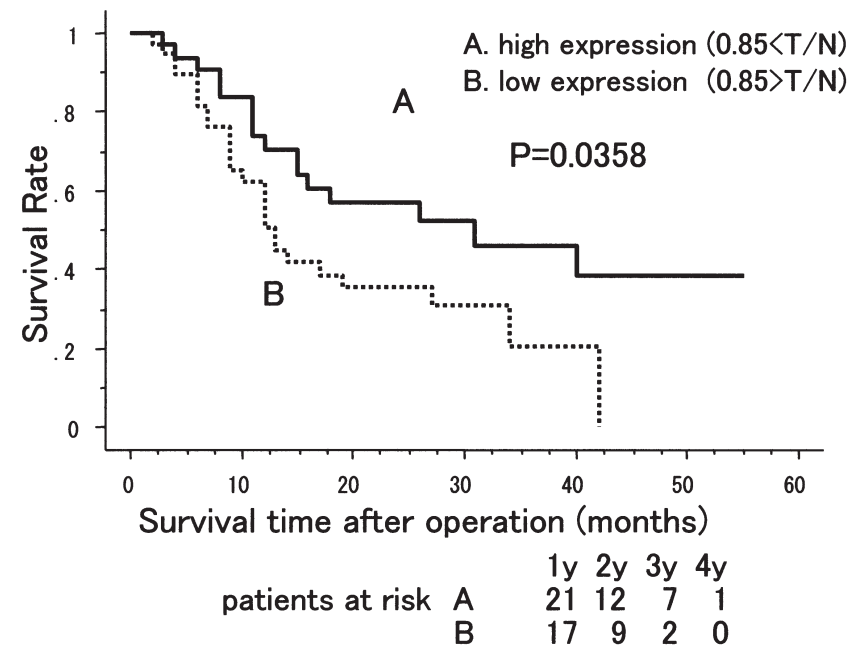

Figure 5. The survival rate of patients with ESCC according to ACP6 mRNA expression. (A) Patients with high ACP6 mRNA expression [indicated by the ratio of $A C P 6 \mathrm{mRNA}$ expression in the tumor to $A C P 6$ mRNA expression in normal esophageal mucosa (tumor:normal) $>0.85, \mathrm{n}=32$ ]. (B) Patients with low ACP6 mRNA expression (tumor:normal $<0.85, \mathrm{n}=38$ ). Patients with high ACP6 mRNA expression had a significantly longer survival than patients with low ACP6 mRNA expression ( $\mathrm{P}=0.0358$, log-rank test).

\section{Discussion}

The ACP6 gene encodes a 458-amino-acid protein with a molecular mass of $51.9 \mathrm{kDa}$. The ACP6 mRNA with a complete length of $1811 \mathrm{bp}$ is expressed ubiquitously and most often in the kidney, heart, small intestine, muscle and liver. The ACP6 gene is located on chromosome 1 at $1 \mathrm{q} 21$, and immunohistochemical analysis demonstrated that ACP6 was shown to localize to the mitchondria (10). The previous report indicated that the cells that expressed ACP6 showed reduction of phosphatidylglycerol (PG) and cardiolipin (10). Cardiolipin is involved in the mitochondrial electron carrier proteins and transport and is essential for cell viability and the pathways that initiate programmed cell death (13). PG is a potential activator of the protein kinase $C$ family (14), which is essential for subsequent responses such as cell proliferation and differentiation (15). PG and cardiolipin are synthesized mainly in mitochondria from LPA. Therefore, increased expression of ACP6 is expected to reduce PA through the hydrolysis of LPA to MAG, resulting in the reduction of cardiolipin and PG (10) (Fig. 1). ACP6 might regulate mitochondrial phospholipid levels.

In our study, the ACP6 mRNA expression level correlated significantly with local invasiveness ( $\mathrm{T}$ factor), lymph node metastasis, and the prognosis of ESCC patients. Patients whose tumors expressed a higher level of ACP6 mRNA survived longer than those whose tumors expressed a lower level of ACP6 mRNA. In multivariate analysis, ACP6 expression ( $\mathrm{T}: \mathrm{N}$ ratio) was an independent prognostic factor together with local invasiveness and lymph node metastasis. Thus, decreased expression of ACP6 may contribute to tumor growth and lymph node metastasis in esophageal cancer. We suppose that the decreased expression of ACP6 may lead to cancer cell proliferation and migration by regulating mitochondrial lipid metabolism including PG and cardiolipin. However, the 
precise function of ACP6 remains unknown and will need to be investigated.

The mechanism behind down-regulation of ACP6, including DNA methylation, mutation and loss of heterozygosity (LOH), was not examined in this study. However, $\mathrm{LOH}$ in this chromosomal locus of ACP6 (1q21) has been detected and was suggested to harbor the putative tumor suppressor gene within this region (1q21) (16). ACP6 could be a candidate tumor suppressor gene. The promoter region of $A C P 6$ contains $\mathrm{CpG}$ islands, suggesting a role of methylation in silencing ACP6 mRNA expression.

Among cancers of the digestive tract, esophageal squamous cell carcinoma (ESCC) has the poorest prognosis. Therefore, it is important to identify prognostic factors for patients with this disease. Several genes, including cyclinD1 (16), PCNA (16), MMP7 (17), p21 (18) and p97 (19), have been reported as independent prognosis factors in patients with ESCC. In this study, we have reported for the first time the relationship between $A C P 6$ and tumor progression and suggested that $A C P 6$ could be a good candidate prognosis marker in esophageal cancer.

\section{Acknowledgements}

The authors thank Ms. Shinobu Makino for her excellent technical assistance.

\section{References}

1. Kato J, Kuwabara Y, Mitani M, et al: Expression of survivin in esophageal cancer: correlation with the prognosis and response to chemotherapy. Int J Cancer 95: 92-95, 2001.

2. Konishi S, Ishiguro H, Shibata Y, et al: Decreased expression of DFF45/ICAD is correlated with a poor prognosis in patients with esophageal carcinoma. Cancer 95: 2473-2478, 2002.

3. Shibata Y, Haruki N, Kuwabara Y, et al: Expression of PTTG (pituitary tumor transforming gene) in esophageal cancer. Jpn J Clin Oncol 32: 233-237, 2002.

4. Shibata Y, Haruki N, Kuwabara Y, et al: Chfr expression is downregulated by $\mathrm{CpG}$ island hypermethylation in esophageal cancer. Carcinogenesis 23: 1695-1699, 2002.

5. Terashita Y, Sasaki H, Haruki N, et al: Decreased peroxisome proliferator-activated receptor gamma gene expression is correlated with poor prognosis in patients with esophageal cancer. Jpn J Clin Oncol 32: 238-243, 2002.
6. Terashita $\mathrm{Y}$, Ishiguro $\mathrm{H}$, Haruki $\mathrm{N}$, et al: Excision repair cross complementing 3 expression is involved in patient prognosis and tumor progression in esophageal cancer. Oncol Rep 12: 827-831, 2004.

7. Chakraborty TR, Vancura A, Balija VS and Haldar D: Phosphatidic acid synthesis in mitochondria. Topography of formation and transmembrane migration. J Biol Chem 274: 29786-29790, 1999.

8. Brindley DN, English D, Pilquil C, Buri K and Ling ZC: Lipid phosphate phosphatases regulate signal transduction through glycerolipids and sphingolipids. Biochim Biophys Acta 1582: 33-44, 2002.

9. Hiroyama $\mathbf{M}$ and Takenawa T: Purification and characterization of a lysophosphatidic acid-specific phosphatase. Biochem J 336 (Pt 2): 483-489, 1998.

10. Hiroyama $\mathrm{M}$ and Takenawa $\mathrm{T}$ : Isolation of a cDNA encoding human lysophosphatidic acid phosphatase that is involved in the regulation of mitochondrial lipid biosynthesis. J Biol Chem 274: 29172-29180, 1999.

11. Tanaka M, Kishi Y, Takanezawa Y, Kakehi Y, Aoki J and Arai H: Prostatic acid phosphatase degrades lysophosphatidic acid in seminal plasma. FEBS Lett 571: 197-204, 2004.

12. Japanese Society for Esophageal Disease: Guidelines for the clinical and pathologic studies on carcinoma of the esophagus. 9th edit., Kanehara Publ. Co., Tokyo, 1999.

13. McMillin JB and Dowhan W: Cardiolipin and apoptosis. Biochim Biophys Acta 1585: 97-107, 2002.

14. Murray NR and Fields AP: Phosphatidylglycerol is a physiologic activator of nuclear protein kinase C. J Biol Chem 273: 11514-11520, 1998.

15. Nishizuka Y: Intracellular signaling by hydrolysis of phospholipids and activation of protein kinase C. Science 258: 607-614, 1992.

16. Zhu SC, Li R, Wang YX, Feng W, Li J and Qiu R: Impact of simultaneous assay, the PCNA, cyclinD1, and DNA content with specimens before and after preoperative radiotherapy on prognosis of esophageal cancer-possible incorporation into clinical TNM staging system. World J Gastroenterol 11: 3823-3829, 2005.

17. Yamashita K, Mori M, Shiraishi T, Shibuta K and Sugimachi K: Clinical significance of matrix metalloproteinase- 7 expression in esophageal carcinoma. Clin Cancer Res 6: 1169-1174, 2000.

18. Natsugoe S, Nakashima S, Matsumoto M, et al: Expression of p21 WAF1/Cip1 in the p53-dependent pathway is related to prognosis in patients with advanced esophageal carcinoma. Clin Cancer Res 5: 2445-2449, 1999.

19. Yamamoto S, Tomita Y, Hoshida Y, et al: Expression level of valosin-containing protein (p97) is associated with prognosis of esophageal carcinoma. Clin Cancer Res 10: 5558-5565, 2004. 